\title{
Relationships of Physical Job Tasks and Living Conditions with Occupational Injuries in Coal Miners
}

\author{
Ashis BHATTACHERJEE ${ }^{1}$, Jean-Pierre BERTRAND ${ }^{2}$, Jean-Pierre MEYER ${ }^{3}$, \\ Lahoucine BENAMGHAR ${ }^{4}$, Carmen OTERO SIERRA ${ }^{4}$, Jean-Pierre MICHAELY ${ }^{4}$, \\ Apurna Kumar GHOSH', Alphonse d'HOUTAUD', Jean-Marie MUR ${ }^{4}$, \\ Nearkasen CHAU ${ }^{4-7 *}$ and Lorhandicap Group ${ }^{4,5}$
}

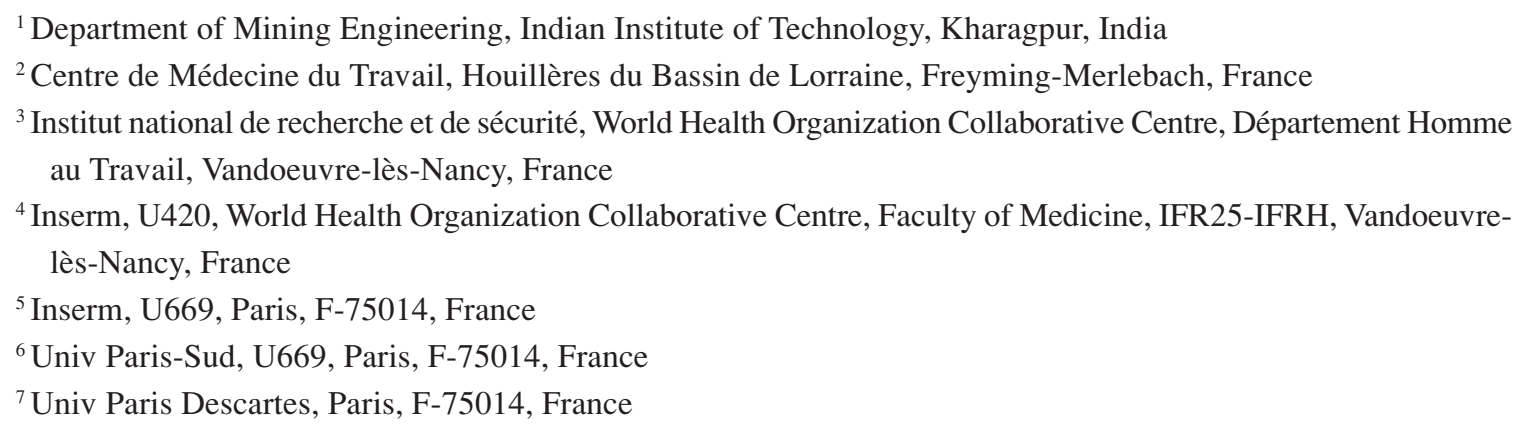

Received July 5, 2006 and accepted December 15, 2006

\begin{abstract}
This study assessed the relationships of job tasks and living conditions with occupational injuries among coal miners. The sample included randomly selected 516 underground workers. They completed a standardized self-administred questionnaire. The data were analyzed via logistic regression method. The rate of injuries in the past two years was $29.8 \%$. The job tasks with significant crude relative risks were: power hammer, vibrating hand tools, pneumatic tools, bent trunk, awkward work posture, heat, standing about and walking, job tasks for trunk and upper/lower limbs, pain caused by work, and muscular tiredness. Logistic model shows a strong relationship between the number of job tasks (JT) and injuries (adjusted ORs vs. JT 0-1: 2.21, 95\% CI 1.27-3.86 for JT 2-6 and 3.82, 2.14-6.82 for $\mathrm{JT} \geq 7$ ), and significant $\mathrm{ORs} \geq 1.71$ for face work, not-good-health-status, and psychotropic drug use. Musculoskeletal disorders and certain personality traits were also significant in univariate analysis. Therefore job tasks and living conditions strongly increase the injuries, and occupational physicians could help workers to find remedial measures.
\end{abstract}

Key words: Occupational injuries, Physical job tasks, Individual factors, Living conditions, Health status

The occupational injuries are common and result in severe socio-economical consequences ${ }^{1)}$. The most affected categories of workers are those with a wide range of job tasks $^{1-3)}$, and several studies have shown the role of work environment, working conditions, job stress and job dissatisfaction in injuries ${ }^{4-7)}$. In France, coal mining

*To whom correspondence should be addressed. employed 11,500 miners, and 10,046 of them were employed in the Lorraine collieries located in north-eastern region. The coal miners are daily exposed to a number of demanding job tasks and are among the workers with the highest incidence rate of occupational injuries ${ }^{1)}$. Furthermore, notgood-health-status and certain diseases, especially the musculoskeletal disorders, are common among the workers ${ }^{1)}$ and they are associated with an increased risk of occupational 
injuries ${ }^{4)}$. The knowledge of the role of various job tasks, health status, and other determinants such as ages, obesity, sleeps disorders, smoking, alcohol use, and personality traits ${ }^{4,8-14)}$ would be helpful when designing preventive measures. However, we are unaware of investigations carried out to simultaneously examine the role of a wide range of job tasks and of the other correlates of occupational injuries. This study assessed the role of a number of job tasks, age, obesity, health status, musculoskeletal disorders, other diseases, personality traits, frequent psychotropic drug use, smoking habit, and alcohol use in occupational injuries in coal miners. The workers studied have been employed with the same jobs for many years, their jobs are demanding but well determined so that their main hazards could be assessed as they are well identified by the occupational physicians.

The sample included 700 male workers randomly selected among all the miners, aged $32-47 \mathrm{yr}$, who worked in underground mines from the Lorraine collieries. The limitation to the age group 32-47 yr was explained by two reasons: to have sufficient exposure duration, and the miners are retired after $48 \mathrm{yr}$. Out of 700 coal miners contacted, 516 subjects participated in the study $(74 \%)$. The investigation had received a favorable view from the "Comité Consultatif pour la Protection des Personnes se prêtant à des Recherches Biomédicales" and the "Commission Nationale de l'Informatique et des Libertés", and a written consent was obtained from the participants.

The miners were invited to the occupational medicine center for medical examination. The study protocol included: (1) a letter requesting participation with a standardized autoquestionnaire given by the occupational physician during medical examination; then (2) two solicitations with questionnaires were sent to miners' home addresses through Post Office at two-month interval. The anonymous standardized auto-questionnaires were completed by the subjects themselves and were sent back to the Inserm unit via pre-paid envelops. The questionnaire included: birth date, height, weight, workplace (face work which deals with extraction of coal, or elsewhere), years worked in underground coal mine, various job tasks, smoking habit, tobacco consumption during the life, excess of alcohol use via the DETA questionnaire (including four items: (i) consumption considered as excessive by the subject himself/ herself, (ii) by people round about the subject, (iii) wish to reduce the consumption, and (iv) consumption on waking; an excess of consumption was defined by at least two positive responses out of these four items $\left.{ }^{15}\right)$, self-reported personality, perceived health-status (Good / Average, poor or bad), various diseases diagnosed by the physician, frequent "psychotropic" drug use (for headache, tiredness, nervousness or anxiety, insomnia $)^{16)}$, and the presence of at least one occupational injury during the previous two-year period. Concerning the job tasks, subjects were asked to indicate the demanding level of the following job tasks (19 items) for their work for the period before and until the occurring of the last occupational injury (High or very high / Absent, low or moderate): use of hammer, power hammer, pneumatic tools, other vibrating hand tools, vibrating platform, bent trunk, awkward posture, noise, heat, standing about and walking, restricted space, tasks at height, work in adverse climate, handling objects, overall job tasks for trunk, upper limbs and lower limbs, pain caused by work, and muscular tiredness at the end of a working day ${ }^{17,18)}$. With regard to personality, subjects were asked whether they considered themselves: worried, not-sociable, not-organized, aggressive $\left(\right.$ Yes / No ${ }^{16,199}$. The occupational injury was defined as damage to body which resulted from an accident at work with a sick leave of at least one day in addition to the day when the accident occurred and for which the subject got compensation. A two-year period was chosen to have a sufficient number of occupational injuries.

The outcome variable was the occurrence of one or more occupational injuries in the past two years. The risk factors studied were: face work, years in underground mine, 19 items on job tasks, age, obese ${ }^{20)}$, smoking habit, excess alcohol use, frequent psychotropic drug use, musculoskeletal disorders, other diseases, and self-reported personality. For the job tasks, the principal component analysis was first made to verify their unidimensionality ${ }^{21)}$; and those items were only considered which were significantly related to injury $(p<0.05)$ (Table 1). Then the overall score of the job tasks was defined by the number of these items. Similarly for personality, a score was defined by the number of the 3 items (not-sociable, not-organized, aggressive) significantly related to injuries. The relationships between various risk factors and injury were examined via the $\chi^{2}$ independence test and crude relative risks (RR), then via the logistic regression method.

The characteristics of the subjects are shown in Table 1. The rate of the occupational injuries in the past two years was $29.8 \%$. About half of miners had worked at face location and $28.7 \%$ had worked for more than $20 \mathrm{yr}$ in underground mine. Most workers were exposed to several job tasks: $38.6 \%$ to $2-6$ and $28.7 \%$ to 7 or more. Face work, muscular tiredness at the end of the working day and pain caused by work were highly related with injuries (crude relative risks RRs $>2$ ). The other job tasks (using power hammer, vibrating hand tools, pneumatic tools, bent trunk, awkward work posture, 
Table 1. Crude relative risks (RR) and $95 \%$ confidence intervals for various factors for occupational injuries (516 subjects)

\begin{tabular}{|c|c|c|c|}
\hline & $\%$ & Crude RR & $95 \% \mathrm{CI}$ \\
\hline Age $<40$ yr & 56.8 & 0.86 & $0.66-1.13$ \\
\hline Obese (body mass index $\geq 30 \mathrm{~kg} / \mathrm{m}^{2}$ ) & 18.8 & 1.27 & $0.94-1.72$ \\
\hline Current smokers & 40.7 & 0.98 & $0.75-1.29$ \\
\hline Excess alcohol use & 11.4 & 1.09 & $0.73-1.62$ \\
\hline $\begin{array}{l}\text { Frequent psychotropic drug use (against tiredness, } \\
\text { nervousness or anxiety, headache, or insomnia) }\end{array}$ & 29.3 & $1.59^{\ddagger}$ & $1.22-2.06$ \\
\hline "Not-good-health" & 52.5 & $1.63^{\ddagger}$ & $1.23-2.17$ \\
\hline Musculoskeletal disorders ${ }^{\mathrm{a}}$ & 54.3 & $1.40^{*}$ & $1.06-1.84$ \\
\hline Disease(s) other than musculoskeletal disorders ${ }^{\mathrm{a}}$ & 30.6 & 1.03 & $0.77-1.36$ \\
\hline \multicolumn{4}{|l|}{ Self-reported personality } \\
\hline Worried & 19.0 & 1.25 & $0.92-1.70$ \\
\hline Not-sociable & 54.3 & $1.32 *$ & $1.01-1.74$ \\
\hline Aggressive & 5.4 & $1.61^{*}$ & $1.05-2.45$ \\
\hline Not-organized & 63.4 & $1.36^{*}$ & $1.01-1.82$ \\
\hline Score $^{\text {b: }} 2-3$ vs. $0-1$ & 43.4 & $1.41^{\dagger}$ & $1.08-1.83$ \\
\hline Face work & 48.8 & $2.03^{\ddagger}$ & $1.53-2.70$ \\
\hline Years worked in underground coal mine $\geq 20$ & 28.7 & 0.87 & $0.64-1.19$ \\
\hline \multicolumn{4}{|l|}{ Demanding job tasks (high or very high levels) } \\
\hline Hammer & 21.5 & 1.32 & $0.99-1.77$ \\
\hline Power hammer & 34.5 & $1.67^{\ddagger}$ & $1.29-2.16$ \\
\hline Vibrating hand tools (other than pneumatic tools) & 29.1 & $1.83^{\ddagger}$ & $1.42-2.36$ \\
\hline Pneumatic tools & 23.8 & $1.45^{\dagger}$ & $1.10-1.91$ \\
\hline Vibrating platform & 33.1 & $1.68^{\ddagger}$ & $1.30-2.18$ \\
\hline Bent trunk & 39.0 & $1.53^{\ddagger}$ & $1.18-1.98$ \\
\hline Awkward posture & 34.5 & $1.58^{\ddagger}$ & $1.22-2.05$ \\
\hline Noise & 60.1 & 1.27 & $0.96-1.68$ \\
\hline Heat & 28.5 & $1.35^{\dagger}$ & $1.03-1.78$ \\
\hline Standing about and walking & 25.0 & $1.36^{*}$ & $1.03-1.79$ \\
\hline Restricted space & 17.2 & 1.31 & $0.96-1.78$ \\
\hline Tasks at height & 24.8 & 1.03 & $0.76-1.39$ \\
\hline Work in adverse climate (bad weather) & 19.0 & 1.03 & $0.74-1.44$ \\
\hline Handling objects & 42.4 & 1.22 & $0.94-1.59$ \\
\hline Overall job tasks for trunk & 38.2 & $1.75^{\ddagger}$ & $1.35-2.27$ \\
\hline Overall job tasks for upper limbs & 40.1 & $1.53^{\ddagger}$ & $1.18-1.99$ \\
\hline Overall job tasks for lower limbs & 35.5 & $1.60^{\ddagger}$ & $1.23-2.07$ \\
\hline Pain caused by work & 29.8 & $2.01^{\ddagger}$ & $1.56-2.59$ \\
\hline Muscular tiredness at the end of a working day & 43.4 & $2.22^{\ddagger}$ & $1.68-2.92$ \\
\hline \multicolumn{4}{|l|}{ Number of these job tasks ${ }^{\mathrm{c}}$ : vs. $0-1$} \\
\hline $2-6$ & 38.6 & 2.04 & $1.34-3.10$ \\
\hline 7 or more & 28.7 & $3.15^{\ddagger}$ & $2.11-4.69$ \\
\hline
\end{tabular}

${ }^{*} p<0.05,{ }^{\dagger} p<0.01,{ }^{\ddagger} p<0.001$.

a $21.3 \%$ of the sample suffered from both musculoskeletal disorders and an other disease. ${ }^{\mathrm{b}}$ Sum of the 3 items (with value $1=$ Yes, and $0=\mathrm{No}$ ) significantly related to occupational injuries (Table 2).

${ }^{\mathrm{c}}$ The factors related with occupational injuries to $p<0.05$ were only considered.

heat, standing about and walking, and overall job tasks for trunk and for upper and lower limbs) were also highly associated with the injuries $(1.22 \leq \mathrm{RRs} \leq 1.83)$ except for tasks at height and work in adverse climate. It should be noted that these job tasks were unidimensional as the Cronbach alpha was high (0.88), and the first three eigenvalues of the principal component analysis were: 5.4, 1.5, 1.0 (the first eigenvalue being much higher than the other eigenvalues) ${ }^{21)}$. A significant relative risk was also found for not-good-healthstatus, musculoskeletal disorders, frequent psychotropic drug 
Table 2. Adjusted odds ratios (OR) and $95 \%$ confidence intervals for various factors for occupational injuries computed with logistic regression model (516 subjects)

\begin{tabular}{lcc}
\hline & Adjusted OR & $95 \%$ CI \\
\hline Face work & $2.29^{\ddagger}$ & $1.49-3.52$ \\
Age $<40 \mathrm{yr}$ & 1.11 & $0.70-1.75$ \\
Obese & 1.44 & $0.86-2.41$ \\
Years worked in underground coal mine $\geq 20$ & 0.69 & $0.42-1.14$ \\
Current smokers & 0.72 & $0.45-1.14$ \\
Excess alcohol use & 0.92 & $0.49-1.75$ \\
Frequent psychotropic drug use & $1.70^{*}$ & $1.09-2.64$ \\
Not-good-health & $1.76^{*}$ & $1.12-2.77$ \\
Musculoskeletal disorders & 1.25 & $0.79-1.98$ \\
Presence of a disease other than musculoskeletal disorders & 0.86 & $0.54-1.36$ \\
Self-reported personality score: $2-3$ vs. 0-1 & 1.41 & $0.93-2.14$ \\
Number of demanding job tasks & & \\
2-6 vs. $0-1$ & $2.21^{\ddagger}$ & $1.27-3.86$ \\
7 or more vs. $0-1$ & $3.82^{\ddagger}$ & $2.14-6.82$ \\
\hline
\end{tabular}

$* p<0.05,{ }^{\dagger} p<0.01,{ }^{\star} p<0.001$.

use, being "not-sociable", "aggressive" or "not-organized".

Table 2 shows a strong association between the number of job tasks (JT) and injuries (adjusted ORs vs. JT 0-1: 2.21 for JT 2-6 and 3.82 for $\mathrm{JT} \geq 7$ ), and reveals significant OR of about 2 for face work, and about 1.70 for not-good-healthstatus and frequent psychotropic drug use.

The present study shows a strong association between the job tasks (JT) and occupational injuries, and that face work, frequent psychotropic drug use, not-good-health-status, musculoskeletal disorders, and certain personality traits were also strongly related to injuries in coal miners. It shows that simultaneous investigating the job tasks and other determinants provides a better understanding of the mechanisms of injuries. The choice of these workers were explained by several reasons. They had been working for a long period in underground mine (mean duration 18 (SD 4) yr). Therefore, they have a good knowledge on job and work conditions. The jobs were demanding but were well determined so that the assessment of job tasks was possible. The rate of injuries with sick leaves in the past two years was high: $29.8 \%$ vs. the annual incidence rate of $10 \%$ for the French construction industry and $4.3 \%$ for 17.2 million working people from the general compensation system ${ }^{11}$. Their age range resulted from a reduction of recruitment and retirement at an early age. We did not calculate the incidence rate of injuries by hours worked as they were the same for all miners during a working year.

The survey using a standardized questionnaire was completed with a very high participation rate (74\%). Only one subject refused. This success could be explained by the motivation of the occupational physicians and the miners involved and the fact that the questionnaire was anonymous. However, the interpretation of the results needs caution due to a possible selection bias and the use of an autoquestionnaire. Note that the use of an auto-questionnaire is reliable and valid ${ }^{22}$. A study analyzing the non-response bias in a mailed health survey showed that the respondents and non-respondents were of similar sex and age distributions and the proportion of persons who had a health care expenditure was very slightly higher in respondents $(75 \%$ vs. $69 \%)^{23)}$. On the other hand, our study had another limitation that the occupational factors and living conditions just before the occupational injuries were assessed retrospectively by the subjects.

The various factors studied were validated and used in several studies ${ }^{4,8,9,12,15-19)}$. They concerned the period before and around the injury occurring. Regarding self-reported personality traits and various job tasks, it was appropriate to calculate their global scores as they were unidimensional and positively linked with injuries. The JT represented a global occupational exposure index; it was divided into three groups with sufficient number of subjects in each group: JT $0-1$, JT $2-6$, and JT $\geq 7$; the middle group included the values around the mean value (4.3 SD (3.9)). In fact most workers performed multi-skilled jobs and they were consequently exposed to several job tasks. We did not take into consideration the dust exposure as it rather concerns the respiratory diseases. Similarly the diesel engine exhaust was also not considered as it was moderate at the workplaces.

This study shows that the use of power hammer, vibrating 
hand tools, pneumatic tools, bent trunk, awkward work posture, heat, standing about and walking, overall job tasks for trunk and for upper and lower limbs, pain caused by work and muscular tiredness at the end of the working day, was strongly related to injuries. Note that for the miners studied injuries were generally directly related to the job tasks investigated (non published data). The crude relative risks found for various hazards suggested that those increased the tiredness or affected the posture had higher risks. Noise, restricted space, tasks at height, and adverse climate were not found to influence injuries. Hammer use and handling objects had increased but non significant risks. An important finding was that most miners were exposed to several significant job tasks ( $38.6 \%$ and $28.7 \%$ to $2-6$ and 7 or more respectively) and a strong dose-effect relationship was found between the JT and injuries: adjusted OR 2.18 (95\%CI 1.273.75 ) for JT 2-6 group and 3.82 (2.21-6.73) for JT 7 group compared with JT $0-1$ group. These findings were expected as most miners were exposed to demanding tasks for a long time every day and this exposure affected health status, caused diseases, tiredness and consequently altered the physical and mental abilities of the workers. Our study points out that face workers had higher risk of injuries compared to the other workers. This was also expected as they were exposed to more hazardous work conditions. They always work in changing work environment under freshly exposed roof where ventilation and other environmental conditions could be inadequate resulting in heat, humidity and slippery floor. Thus, the experience and job knowledge cannot eliminate the injuries when the number of demanding hazards is high.

In this study no relationship was found between age and injuries. This was expected as generally the workers with an increased risk are those aged less than 30 or over $50^{8-10}$ ) while there was no subject in these age categories in our study. The miners studied did not have a lack of experience and of job knowledge as they had been with the same jobs for several years.

This study shows that not-good-health-status was a high risk factor of injuries. This was explained by the fact that it also altered the physical or mental abilities of workers. The high prevalence of not-good-health shows the impact of work conditions on health status ${ }^{2,24)}$. Our finding supports the hypothesis that the injuries would increase in the coming years for working population due to the lengthening of working years which would result in more people working with diseases and disabilities. It is thus necessary to improve work conditions to reduce occupational related diseases which in turn will lead to improve health status and living conditions. It may be noted that the miners had worked in teams and most demanding and challenging tasks were performed by the workers with better abilities due to their solidarity and the recommendations of the occupational physicians. It was observed that this organization was not sufficient to prevent the injuries for the miners with notgood-health-status. In the same way, frequent psychotropic drug use was found to predict injuries. This was expected as the drugs considered are related with physical and mental abilities. The workers concerned would have altered abilities of working and watching work conditions and environmental hazards. Our findings are consistent with those from other investigations which emphasized the role of sleep disorders $8,9,11,13,14)$. Sleep disorders influence fatigue, ability, vigilance, difficulty in assessing or watching the work environment ${ }^{25}$ and thus injuries. For self-reported personality, being not-sociable, aggressive and not-organized were found to influence injuries. Similar finding was reported ${ }^{19)}$. Thus, personality could influence the ability of the workers in assessing or watching the work environment and may lead to more injuries.

Our study does not reveal an association between obesity and injuries. It may be noted that obesity was not related with age, JT, and psychotropic drug use. The result found was in agreement with that of other studies which only analyzed individual characteristics but not job tasks ${ }^{8,9)}$. Similarly, obesity did not influence occupational falls but those with longer sick leaves ${ }^{12}$. Our study does not find a higher risk of injuries among the current smokers contrarily to some studies ${ }^{8,9,12)}$. This would be explained by the fact that the miners did not smoke at work so that they were not affected by the adverse short-term effects of smoking ${ }^{12)}$. An excess alcohol use was identified for $11.4 \%$ of the subjects. This prevalence was close to that of the Lorraine working population using the same questionnaire ${ }^{4)}$. An increased risk of injuries was not found in miners with excess alcohol use. Studies of Lorraine's working population and railway workers reported adjusted ORs of about 1.45 for the workers with excess alcohol use, although they were not significant. However, the railway workers with excess alcohol use showed a risk of 4 times higher for certain falls ${ }^{12)}$.

In conclusion, our study shows a strong dose-effect relationship between job tasks and occupational injuries, and that face work, not-good-health-status, musculoskeletal disorders, frequent psychotropic drug use, and some personality traits increased the risk of injuries. Preventive measures should reduce the job tasks, help workers to improve their living conditions, and increase the awareness of the workers about the risk associated with these factors. They should also be focused on the quality of some tools 
and their use, vibrating platform, work posture, heat, standing about and walking, and on the tasks generating excess pain and tiredness.

\section{Acknowledgements}

The authors thank Patrick Gall, the staff of the occupational medicine center of the Houillères du Bassin de Lorraine, M. Weis, D. Saouag for their valuable contribution to the study.

\section{Lorhandicap Group}

The group includes N. Chau, F. Guillemin, J.F. Ravaud, J. Sanchez, S. Guillaume, J.P. Michaely, C. Otero Sierra, B. Legras, A. Dazord, M. Choquet, L. Méjean, N. TubianaRufi, J.P. Meyer, Y. Schléret, J.M. Mur.

\section{References}

1) Caisse nationale de l'assurance maladie des travailleurs salariés (CNAMTS) (2003) Statistiques nationales des accidents du travail, des accidents de trajet et des maladies professionnelles, Année 2001, CNAMTS, Paris.

2) Jorgensen K (1998) Concepts of accident analysis. In: Encyclopaedia of Occupational Health and Safety, Chapter VIII, Accidents and safety management-Accident prevention, Vol. 3, 4th Ed., International Labour Office (Ed.), ILO, Geneva.

3) Maiti J, Bhattacherjee A, Bangdiwala SI (2001) Loglinear model for analysis of cross-tabulated coal mine injury data. Inj Control Saf Promot 8, 229-36.

4) Bhattacherjee A, Chau N, Otero Sierra C, Legras B, Benamghar L, Michaely JP, Ghosh AK, Guillemin F, Ravaud JF, Mur JM, Lorhandicap group (2003) Relationships of job and some individual characteristics to occupational injuries in employed people: a community-based study. J Occup Health 45, 382-91.

5) Griffin MA, Neal A (2000) Perceptions of safety at work: a framework for linking safety climate to safety performance, knowledge and motivation. J Occup Health Psychol 5, 34758.

6) Melamed S, Yekutieli D, Froom P, Kristal-Boneh E, Ribak J (1999) Adverse work and environmental conditions predict occupational injuries: the Israeli cardiovascular occupational risk factors determination in Israel (Cordis) study. Am J Epidemiol 150, 18-26.

7) Ghosh AK, Bhattacherjee A, Chau N (2004) Relationships of working conditions and individual characteristics with occupational injuries: a case-control study in coal miners. $\mathrm{J}$ Occup Health 46, 470-80.

8) Chau N, Mur JM, Benamghar L, Siegfried C, Dangelzer JL,
Français M, Jacquin R, Sourdot A (2004) Relationships between certain individual characteristics and occupational injuries for various jobs in the construction industry: a casecontrol study. Am J Ind Med 45, 84-92.

9) Gauchard GC, Mur JM, Touron C, Benamghar L, Dehaene D, Perrin P, Chau N (2006) Determinants of accident proneness: a case-control study in railway workers. Occup Med (London) 56, 187-90.

10) Ghosh AK, Bhattacherjee A (2003) Role of individual characteristics of workers in mine accidents: a case-control study. Minetech 24, 43-8.

11) Ulfberg J, Carter N, Edling C (2000) Sleep-disordered breathing and occupational accidents. Scand J Work Environ Health 26, 237-42.

12) Gauchard G, Chau N, Touron C, Benamghar L, Dehaene D, Perrin P, Mur JM (2003) Individual characteristics in occupational accidents due to imbalance: a case-control study in the employees of a railway company. Occup Environ Med 60, 330-5.

13) Nakata A, Ikeda T, Takahashi M, Haratani T, Fujioka Y, Fukui S, Swanson NG, Hojou M, Araki S (2005) Sleep-related risk of occupational injuries in Japanese small and medium-scale enterprises. Ind Health 43, 89-97.

14) Chau N, Benamghar L, Siegfried C, Dehaene D, Dangelzer JL, Français M, Jacquin R, Alain A, Touron C, Mur JM (2006) Determinants of occupational fracture proneness: a casecontrol study in construction and railway workers. J Occup Health 48, 267-70.

15) Baudier F, Arène J (1997) Baromètre santé adultes 95/96, Editions CFES, Paris.

16) Challier B, Chau N, Predine R, Choquet M, Legras B (2000) Associations of family environment and individual factors with tobacco, alcohol and illicit drug uses in adolescents. Eur J Epidemiol 16, 33-42.

17) Lorhandicap group: Chau N, Guillemin F, Ravaud JF, Meyer JP, Sanchez J, Bhattacherjee A, Bourgkard E, Guillaume S, Michaely JP, Otero Sierra C, Legras B, Dazord A, Choquet M, Méjean L, Tubiana-Rufi N, Schléret Y, Mur JM (2004) Relationships between demanding work conditions and occupational injuries: a community-based study. Occup Environ Med 61, e57.

18) Lorhandicap group: Chau N, Ravaud JF, Bourgkard E, Sanchez J, Choquet M, Meyer JP, Otero Sierra C, Michaely JP, Legras B, Guillemin F, Bhattacherjee A, Guillaume S, Dazord A, Méjean L, Tubiana-Rufi N, Schléret Y, Mur JM (2004) Relationships of demanding work conditions with fatigue and psychosomatic disorders: a community-based study. Occup Environ Med 61, e46.

19) Chau N, d'Houtaud A, Gruber M, Monhoven N, Gavillot C, Pétry D, Bourgkard E, Guillaume S, André JM (1995) Personality self-representations of patients with hand injury, and its relationship with work injury. Eur J Epidemiol 11, 373-82.

20) Arome LJ (2002) Classification of obesity and assessment of obesity-related health risks. Obes Res 10, 105s-15s. 
21) Falissard B (1998) Comprendre et utiliser les statistiques dans les sciences de la vie, 2nd Ed., Masson, Paris.

22) Lewis RJ, Friedlander BR, Bhojani FA, Schorr WP, Salatich PG, Lawhorn EG (2002) Reliability and validity of an occupational health history questionnaire. J Occup Environ Med 44, 39-47.

23) Etter JF, Perneger TV (1997) Analysis of non-response bias in a mailed health survey. J Clin Epidemiol 50, 1123-8.
24) Houtman IL, Goudswaard A, Dhondt S, van der Grinten MP, Hildebrandt VH, van der Poel EG (1998) Dutch monitor on stress and physical load: risk factors, consequences, and preventive action. Occup Environ Med 55, 73-83.

25) Härmä M, Suvanto S, Popkin S, Pulli K, Mulder M, Hirvonen K (1998) A dose-response study of total sleep time and the ability to maintain wakefulness. J Sleep Res 7, 167-74. 